\title{
Erratum to: Journal of Computational Neuroscience, DOI 10.1007/s10827-010-0303-y and DOI 10.1007/s10827-010-0304-x
}

\author{
John L. Baker • Tamara Perez-Rosello • \\ Michele Migliore • Germán Barrionuevo • \\ Giorgio A. Ascoli
}

Published online: 12 October 2011

(C) Springer Science+Business Media, LLC 2011

\section{Erratum to:}

Passive and active shaping of unitary responses from associational/commissural and perforant path synapses in hippocampal CA3 pyramidal cells

J Comput Neurosci

DOI 10.1007/s10827-010-0303-y

A computer model of unitary responses from associational/ commissural and perforant path synapses in hippocampal CA3 pyramidal cells

J Comput Neurosci (2011) 31:137-158

DOI 10.1007/s10827-010-0304-x

The online version of the original articles can be found at http://dx.doi. org/10.1007/s10827-010-0303-y and http://dx.doi.org/10.1007/s10827010-0304-x.

J. L. Baker $\cdot$ M. Migliore $\cdot$ G. A. Ascoli $(\bowtie)$

Center for Neural Informatics, Structures, \& Plasticity,

George Mason University,

4400 University Drive, MS 2A1, Fairfax, VA 22030, USA

e-mail: ascoli@gmu.edu

T. Perez-Rosello $\cdot$ G. Barrionuevo

Department of Neuroscience, University of Pittsburgh,

Pittsburgh, PA, USA

T. Perez-Rosello

Department of Otolaryngology,

University of Pittsburgh School of Medicine,

Pittsburgh, PA, USA

Present Address:

M. Migliore

Institute of Biophysics, National Research Council,

Palermo, Italy
Due to a publisher error, "A computer model of unitary responses from associational/commissural and perforant path synapses in hippocampal CA3 pyramidal cells" (Baker et al.), the second in a series of two papers, was published prior to "Passive and active shaping of unitary responses from associational/commissural and perforant path synapses in hippocampal CA3 pyramidal cells" (Perez-Rosello et al.).

Perez-Rosello et al. is an experimental paper, and should be considered first. Baker et al. contains simulations that model, and expand on, the data of Perez-Rosello et al. Springer apologizes for any confusion caused by the nonsequential publication. 